\title{
Surgical management of paediatric pituitary tumours with an endoscopic trans-sphenoidal approach
}

Mr Neil Giblett ${ }^{1}$ Mr Shahzada Ahmed²

Mr Desiderio Rodrigues ${ }^{3}$ Ms Ann-Louise McDermott ${ }^{4}$

Institution

1. Specialist Trainee Registrar in Otolaryngology, West Midlands.

2. Consultant Adult ENT \& Skull Base Surgery, University Hospitals Birmingham.

3. Consultant Paediatric Neurosurgeon, Birmingham Children's Hospital

4. Consultant in Paediatric ENT \& Skull Surgery, Birmingham Children's Hospital

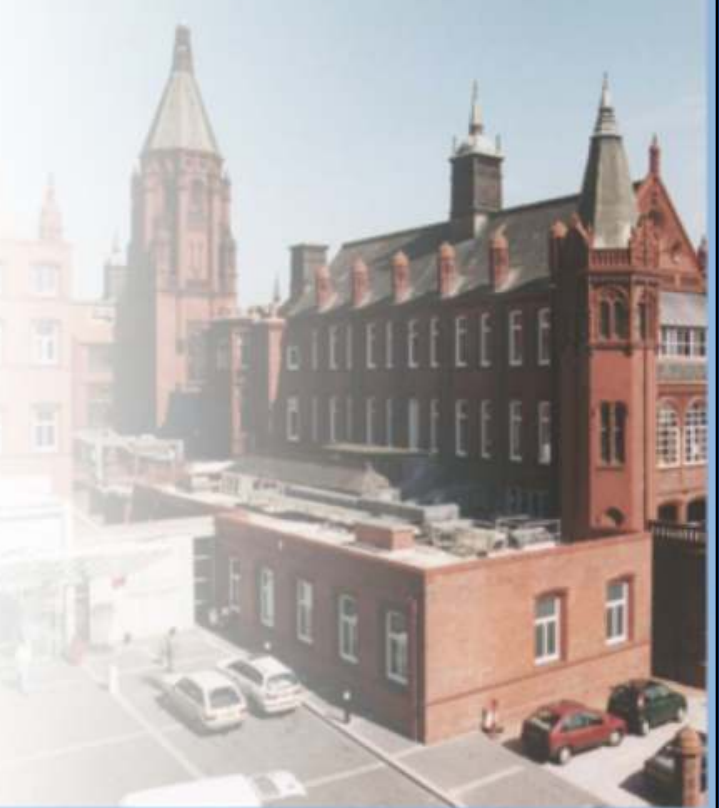

\section{Background:}

Endoscopic transnasal surgery is the mainstay management strategy of pituitary tumours in adults but this approach is more challenging in the paediatric population. This is due to anatomical limitations of the paranasal sinuses, particularly sphenoid development, as well as the practical and equipment issues that arise when planning such surgery. As in adults, a designated multidisciplinary team is essential for the best outcomes.
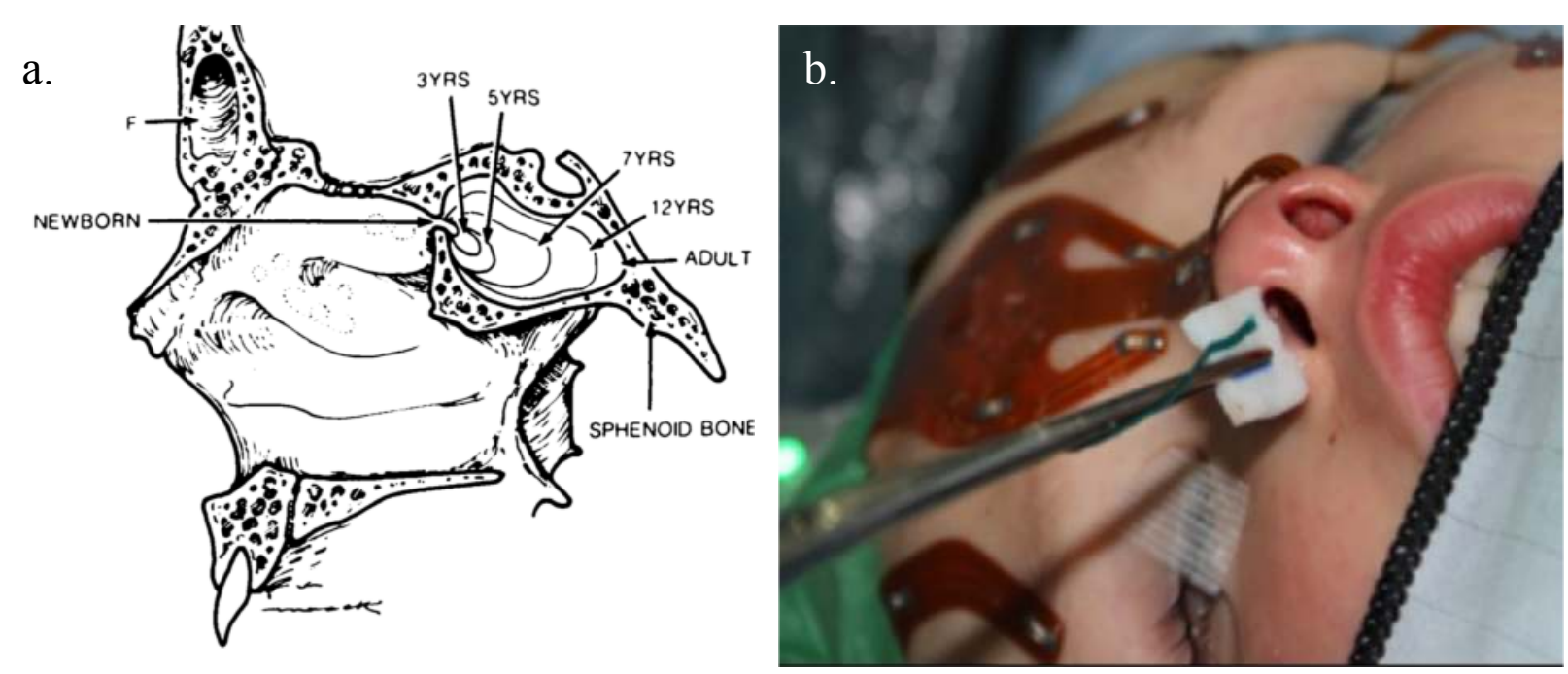

a. Sagittal view of sphenoid sinus development. b. Practical equipment issues with nasal aperture size in a very young child with a pituitary tumour

\section{Objectives:}

To evaluate the effectiveness of endoscopic transnasal surgery in the management of paediatric pituitary tumours.
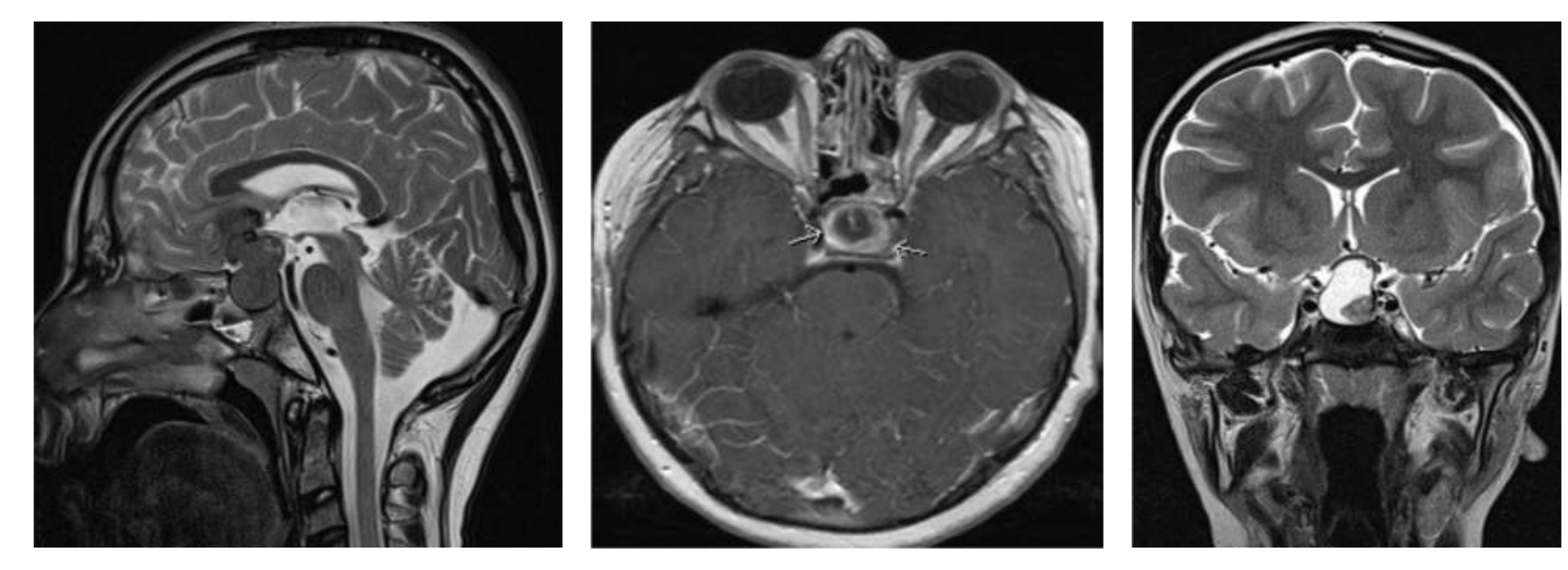

\section{Methods:}

We report our experience of managing paediatric pituitary tumours with an endoscopic transnasal approach at a UK tertiary paediatric centre from 2010 to date.

\section{Results:}

8 males: 7 females

Age range: $5-16$ years

Mean age: 12.4 years

Primary presenting symptoms:

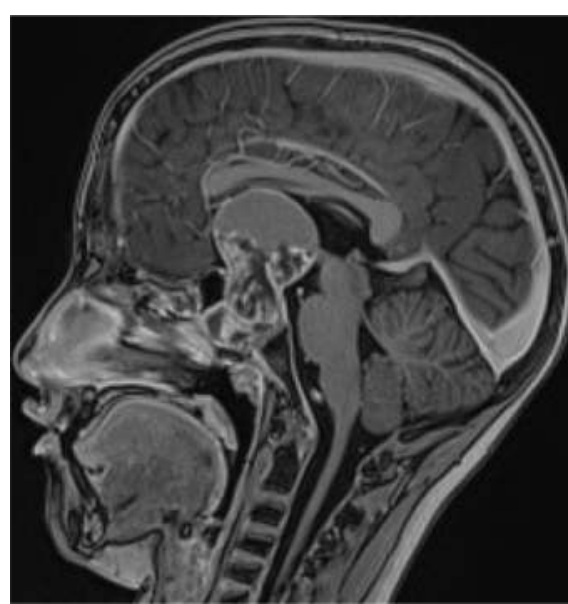

- 3 visual loss

- 5 headaches (secondary to hydrocephalus)

- 5 Cushing syndrome

- 2 Acromegaly

19 procedures were performed on 15 children

- Two children had staged endoscopic transnasal surgeries

- Two children had staged open craniotomy surgery combined with a transnasal procedure

Tumour control has been achieved in all patients

- Follow up $=3$ months to 7 years

\section{Complications:}

Early: (within 4 weeks)

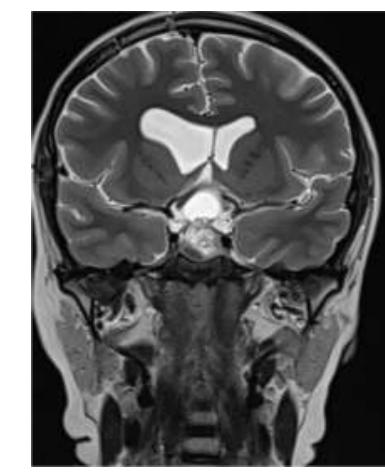

- Haematoma with visual $\mathrm{Sx}$ [n=1; return to theatre for evacuation]

- Extensive nasal crusting requiring regular debridement $[\mathrm{n}=15]$

- Transient hormonal dysfunction $[\mathrm{n}=9]$

- CSF leak [n=1; repaired at $48 \mathrm{hrs}$ ]

Intermediate: (1-12 months)

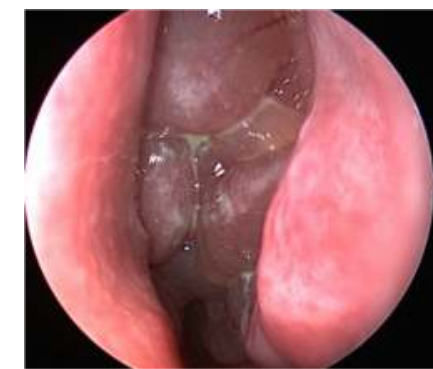

- Persistent crusting and polypoidal mucosal changes [ $\mathrm{n}=3]$

- Persistent hormonal dysfunction requiring medication $[\mathrm{n}=5]$

\section{Late: (after 12 months)}

- VP shunt [n=1]

- Saddle nasal deformity $[\mathrm{n}=4]$

- Permanent hormonal replacement $[\mathrm{n}=3]$

- Cushing's syndrome requiring radiotherapy [n=1]

- Second pituitary tumour [ $\mathrm{n}=1$; acromegaly child, removed at $2 \mathrm{yrs}]$

\section{Conclusion}

Endoscopic transnasal resection of paediatric pituitary tumours is an effective technique even in the very small child. A Multidisciplinary team is essential with experience from both adult and paediatric anterior skull base team members for the best outcomes. 